\title{
Gastric cancer and family history
}

\author{
Yoon Jin $\mathrm{Choi}^{1}$ and Nayoung $\mathrm{Kim}^{1,2}$
}

${ }^{1}$ Department of Internal Medicine, Seoul National University Bundang Hospital, Seongnam; ${ }^{2}$ Department of Internal Medicine and Liver Research Institute, Seoul National University College of Medicine, Seoul, Korea

Received: May 11, 2016

Accepted: October 22, 2016

\section{Correspondence to}

Nayoung Kim, M.D.

Department of Internal

Medicine, Seoul National

University Bundang Hospital, 82

Gumi-ro 173beon-gil,

Bundang-gu, Seongnam 13620,

Korea

Tel: + 82-31-787-7008

Fax: + 82-31-787-4051

E-mail: nayoungkim49@empas.com Keywords: Stomach neoplasms; Family history; Helicobacter pylori
Gastric cancer is associated with high morbidity and mortality rates worldwide. Identifying individuals at high risk is important for surveillance and prevention of gastric cancer. Having first-degree relatives diagnosed with gastric cancer is a strong and consistent risk factor for gastric cancer, but the pathogenic mechanisms behind this familial aggregation are unclear. Against this background, we reviewed the risk factors for gastric cancer in those with a first-degree relative with gastric cancer, and the possible causes for familial clustering of gastric cancer including bacterial factors, inherited genetic susceptibility, environmental factors or a combination thereof. Among individuals with a family history, current or past Helicobacter pylori infection, having two or more first-degree affected relatives or female gender was associated with an increased risk of developing gastric cancer. To date, no specific single nucleotide polymorphism has been shown to be associated with familial clustering of gastric cancer. $H$. pylori eradication is the most important strategy for preventing gastric cancer in first-degree relatives of gastric cancer patients, particularly those in their 20 and 30 . Early $H$. pylori eradication could prevent the progression to intestinal metaplasia and reduce the synergistic effect on gastric carcinogenesis in individuals with both $\mathrm{H}$. pylori infection and a family history. Endoscopic surveillance is also expected to benefit individuals with a family history. Further large-scale, prospective studies are warranted to evaluate the cost-effectiveness and optimal time point for endoscopy in this population. Moreover, genome-wide association studies that incorporate environmental and dietary factors on a 'big data' basis will increase our understanding of the pathogenesis of gastric cancer.

\section{INTRODUCTION}

Gastric cancer is the fifth most common cancer worldwide and ranks as the third leading cause of cancer-related death [1]. Although the age-standardized incidence of gastric cancer has decreased in the last few decades in Japan [2] and Korea [3], the number of new cases is increasing, mainly due to the aging of the population.

Gastric cancer is divided into diffuse and intestinal types based on its histological appearance, and into cardia and non-cardia cancer according to its location [4].
The epidemiological and molecular features of gastric cancer differ according to the histological type and location of the tumor. The most well-established risk factor is Helicobacter pylori infection [5]. In a meta-analysis of 19 cohort or case-control studies, the summary odds ratio (OR) for gastric cancer was estimated to be 1.9 (95\% confidence interval [CI], 1.3 to 2.8) in $\mathrm{H}$. pylori-infected compared to uninfected subjects [6].

A family history of gastric cancer is also a strong risk factor [7]. Although most gastric cancers are sporadic, approximately $10 \%$ show familial aggregation [8]. Inherit- 
ed gastric cancers, which show a Mendelian inheritance pattern, comprise less than $3 \%$ of all gastric cancers and fall into three main autosomal dominant syndromes: hereditary diffuse gastric cancer (HDGC), gastric adenocarcinoma and proximal polyposis of the stomach, and familial intestinal gastric cancer [8]. HDGC is the best known familial gastric cancer, and is characterized by $\mathrm{CDH} 1$ deletion. HDGC is rare (incidence of $0.3 \%$ to $3.1 \%$ in Korea and Japan [9]) and does not account for a large proportion of familial clustering [10]. However, excluding the small portion of familial gastric cancer syndrome, the risk of gastric cancer in those with a family history is approximately threefold greater than in those without such a history, which is higher than that for other solid cancers in adults, with the exception of ovarian cancer [7].

Although family history is a strong and consistently reported risk factor for gastric cancer, the molecular basis for familial aggregation is unclear. Family members have a shared exposure to carcinogens (i.e., nitrogen, cigarette smoke, and alcohol consumption), together with similar levels of hygiene, dietary habits (salty and spicy food, smoked food), bacterial virulence, such as cagA and genetic susceptibility.

Therefore, in this review, we discuss the risk of gastric cancer in subjects with a family history of the disease, and then evaluate the mechanism underlying the increased susceptibility to gastric cancer in individuals with a family history. We also review the prognosis after diagnosis of gastric cancer, and methods for gastric cancer prevention and screening for subjects with a family history of the disease.

\section{FAMILY HISTORY AS A RISK FACTOR FOR GAS- TRIC CANCER}

Although there are limited data on the incidence of familial gastric cancer, the proportion of subjects with a family history of gastric cancer among those undergoing health check-ups has been reported to be $11 \%$ [11] and $11.8 \%$ [12]. While the rate of gastric cancer in individuals with a family history in Asia is higher than in those in Europe or North America, the frequency of HDGC in relation to the incidence of familial gastric carcinogenesis in Asia is low [13]. Therefore, environmental factors rather than genetic factors might contribute to development of familial gastric cancer in countries with a high incidence of the disease.

Although the rates of gastric cancer differ worldwide, the importance of family history as a risk factor for gastric cancer is ubiquitous. Gastric cancer patients exhibit a 2- to 3-fold higher rate of a family history, suggesting that a family history of gastric cancer is an independent risk factor [14-16]. The importance of family history as a risk factor for gastric cancer has been evaluated in case-control studies (Table 1) [17-36]. All studies (eight from Europe, nine from East Asia, one from India, one from the Middle East, and one from the United States) reported general risk ratios of 1.5 to 3.5 (Table 1). The case-control studies from Europe reported relative risks of developing gastric cancer in subjects with a family history of 1.8 to $3.5[17,22,23,37]$. Five studies conducted in different regions of Japan reported ORs ranging from 1.5 to 4.4 [19-21,29,30]. Eto et al. [19] reported an OR of 4.4 (95\% CI, 3.9 to 5.0) after adjustment for age and gender; the overall OR was similar for the intestinal and diffuse subtypes, but among patients diagnosed with gastric cancer before the age of 43 years, the OR for a family history of intestinal-type gastric cancer was 12.5 ( $95 \%$ CI, 4.8 to 32). Nagase et al. [30] studied 136 cases and 136 controls and reported an OR for subjects with first-degree relatives of 2.3 (95\% CI, 1.1 to 5.0). Three studies from Korea have reported ORs ranging from 2.3 to $9.9[18,31,33]$.

Although a diffuse-type histology is required for the diagnosis of HDGC, it seems that intestinal-type of gastric cancer also is related with family history of gastric cancer [22]. Intestinal-type gastric cancer has been reported to develop more frequently in a certain familial setting [19,38]. Intestinal-type gastric cancer in young patients is strongly associated with a family history of gastric cancer in first degree-relatives (OR, 2.5) [19]. Moreover, the risk of intestinal-type gastric cancer is increased (OR, 7.8) in patients whose parents both have the disease [19]. Regarding tumor location, it has been reported that tumors are frequently located in the proximal stomach in patients with a positive family history of gastric cancer [19,39]. Further studies of the histology, location and pattern of familial clustering on gastric cancer are required. 
Table 1. Risk for developing gastric cancer in subjects with family history of gastric cancer

\begin{tabular}{|c|c|c|c|c|c|c|c|}
\hline \multirow{2}{*}{ Study } & \multirow{2}{*}{ Country } & \multirow{2}{*}{ Family history } & \multicolumn{2}{|c|}{ Control } & \multicolumn{2}{|c|}{ Case } & \multirow{2}{*}{$\operatorname{AOR}(95 \% \mathrm{CI})$} \\
\hline & & & No. (\%) & No. & No. (\%) & No. & \\
\hline Lissowska et al. (1999) [22] & Poland & First-degree & $19(4.0)$ & 472 & $59(13.5)$ & 437 & $3.5(2.0-6.2)$ \\
\hline La Vecchia et al. (1992) [23] & Italy & First-degree & $87(4.9)$ & 1776 & $79(12.6)$ & 628 & $2.6(1.8-3.6)$ \\
\hline Palli et al. (2000) [36] & Italy & First-degree & $74(13.2)$ & 561 & $40(31.7)$ & 126 & $1.8(1.6-2.0)$ \\
\hline Foschi et al. (2008) [35] & Italy & First-degree & $31(5 \cdot 7)$ & 547 & $30(13.0)$ & 230 & $2.5(1.5-4.2)$ \\
\hline Brenner et al. (2000) [17] & Germany & First-degree & $12(5.0)$ & 239 & $10(14.7)$ & 68 & $2.9(1.3-6.5)$ \\
\hline $\begin{array}{l}\text { Garcia-Gonzalez et al. } \\
(2007)[24]\end{array}$ & Spain & $\begin{array}{l}\text { One first-degree or two } \\
\text { second-degree relatives }\end{array}$ & $17(7 \cdot 1)$ & 286 & $5^{1}(17.6)$ & 290 & $3.0(1.8-5.0)$ \\
\hline $\begin{array}{l}\text { Gajalakshmi et al. } \\
(1996)[28]\end{array}$ & India & NA & $2(0.5)$ & 388 & $12(3.1)$ & 388 & $5.7(1.3-26)$ \\
\hline Bakir et al. (2000) [25] & Turkey & Siblings & $19(1.5)$ & 1,240 & $168(13.5)$ & 1,240 & $10.1(6.1-16.8)$ \\
\hline Bakir et al. (2003) [26] & Turkey & Parents & $25(2.0)$ & 1,240 & $148(11.9)$ & 1,240 & $6.6(4.2-10.4)$ \\
\hline Safaee et al. (2011) [34] & Iran & First-degree & $18(2.4)$ & 746 & $53(7.1)$ & 746 & $3.3(1.7-6.4)$ \\
\hline Dhillon et al. (2001) [27] & USA & First-degree & $35(5 \cdot 0)$ & 695 & $70(11.1)$ & 629 & $2.2(1.5-3.3)$ \\
\hline Nagase et al. (1996) [30] & Japan & First-degree & $10(7.4)$ & 136 & $21(15.4)$ & 136 & $2.3(1.1-5.0)$ \\
\hline Huang et al. (1999) [21] & Japan & First-degree & $3,608(12.6)$ & 28,619 & $207(23.3)$ & 887 & $1.6(1.28-1.9)$ \\
\hline Ikeguchi et al. (2001) [20] & Japan & First/second/third-degree & $254(12.4)$ & 2,052 & $216(23.3)$ & 926 & $2.2(1.8-2.6)$ \\
\hline Minami et al. (2003) [29] & Japan & First-degree & $369(15.1)$ & 2,444 & $140(22.8)$ & 614 & $1.5(1.3-1.8)$ \\
\hline Eto et al. (2006) [19] & Japan & First-degree & $1,475(11.0)$ & 13,467 & $543(38.8)$ & 1,400 & $4 \cdot 4(3 \cdot 9-5 \cdot 0)$ \\
\hline Chen et al. (2004) [32] & Taiwan & First-degree & $54(9 \cdot 3)$ & 579 & $47(26.7)$ & 176 & $2.5(1.3-4.8)$ \\
\hline Hong et al. (2006) [31] & Korea & First-degree & $21(8.8)$ & 238 & $94(87.0)$ & 108 & $9.9(6.5-15)$ \\
\hline Shin et al. (2010) [18] & Korea & First-degree & $33(9.0)$ & 368 & $90(21.0)$ & 428 & $2.9(1.8-4.5)$ \\
\hline Gong et al. (2014) [33] & Korea & First-degree & $31(9.5)$ & 327 & $61(18.7)$ & 327 & $2.3(1-3-4.0)$ \\
\hline
\end{tabular}

AOR, adjusted odds ratios for age, sex and other covariates; CI, confidence interval; NA, not available.

\section{H. pylori infection rate in subjects with and without affected relatives}

The $H$. pylori infection rate is decreasing due to improved socioeconomic conditions and sanitation. For example, the $H$. pylori seroprevalence among Koreans older than 16 years of age was 59.6\% and 54.4\% in 2005 and in 2011, respectively [11,40], a considerable decrease from 66.9\% in 1998 [41]. Additionally, in the Czech Republic, the prevalence decreased dramatically from $41.7 \%$ [42] to $23.5 \%$ [43] between 2001 and 2011.

The $\mathrm{H}$. pylori infection rate is higher in subjects with than without a family history of gastric cancer [44,45]. These results were in accordance with a Korean study [16]. However, a nationwide epidemiological survey involving 10,796 Korean subjects who participated in health check-ups in 2011 reported that the $H$. pylori seropositive rate in subjects with a family history was not significantly different from that of subjects without a family history (55.1\% vs. 54.4\%) [11]. This result was similar to those reported in 1998 [41] and in 2005 [40]. Therefore, a difference in $\mathrm{H}$. pylori infection rate is not responsible for the increased risk of gastric carcinogenesis in first-degree family members of gastric cancer patients.

Relatives with gastric cancer are significantly and independently more frequently colonized by $H$. pylori strains with higher numbers of CagA-EPIYA-C segments (OR, 4.2; 95\% CI, 1.5 to 11.7) and of the most virulent genotype sımı vacA (OR, 2.80; 95\% CI, 1.0 to 7.5) [46]. In contrast, it has been reported that $H$. pylori genotypes such as vacA s1 cagA might not be important determinants of the type and advanced form of gastritis in the first-degree relatives of gastric cancer patients [47]. Therefore, further comprehensive research is needed. 


\section{Risk increment in subjects with both $\mathrm{H}$. pylori infec- tion and a family history}

$H$. pylori infection and having a first-degree relative with gastric cancer are positively related. One study from Germany reported that subjects with both a family history and infection with a CagA-positive $H$. pylori strain had a more than eightfold higher risk of gastric cancer (OR, 8.2; 95\% CI, 2.2 to 30.4) and a 16-fold higher risk of noncardia gastric cancer (OR, 16.0; 95\% CI, 3.9 to 66.4) compared with uninfected subjects who had no family history [17]. A Korean study also showed that the relative excess risk for patients with both $\mathrm{H}$. pylori infection and a family history of gastric cancer exceeded the sum of the relative excess risks for each risk factor alone: 5.32 $-1.00>(1.58-1.00)+(1.33-1.00)$ [18]. A Japanese study showed that women with both a family history and $H$. pylori infection had a more than fivefold increased risk of gastric cancer (OR, 5.10; 95\% CI, 1.58 to 16.5) compared to those without these factors [48].

The relation between a family history of the disease and the risk of gastric cancer is reduced somewhat by control of $\mathrm{H}$. pylori infection. This implies that intrafamilial aggregation of gastric carcinoma may be due, at least in part, to intrafamilial clustering of $\mathrm{H}$. pylori infection. However, a strong relationship between a family history and an increased risk of gastric carcinoma remained after control of $H$. pylori infection, suggesting that other factors, such as genetic or lifestyle factors, contribute to the familial clustering of gastric cancer.

\section{Genetic predisposition in gastric cancer patients with a family history}

Familial risk is a hallmark of genetic susceptibility. However, with the exception of HGDC, no genetic screening has been recommended [8]. Regarding the genetic aspect of gastric carcinogenesis, familial aggregation may be the result of a number of low-penetrant alleles acting in combination, rather than one or a few highly penetrant dominant cancer genes [7]. Several genes-such as interleukin $1 \beta(I L-1 \beta)$, tumor necrosis factor $\alpha(T N F-\alpha)$, IL-6, IL-S, IL-10, Toll-like receptor 4 (TLR-4), and transforming growth factor $\beta$ (TGF- $\beta$ ) -are suspected to affect susceptibility to $H$. pylori infection or to moderate local inflammation [49-51].

El-Omar et al. [49] first reported an association between the $I L-1 \beta-31 C$ and $I L-1 R N \quad 2 / 2$ genotypes with a higher risk of chronic hypochlorhydria and gastric cancer. The presence of $I L-1 \beta-511 \mathrm{~T}, I L-1 R N^{*} 2 /{ }^{*} 2$, TNF$\alpha-308$ A, and IL-10 (haplotype ATA/ATA) was associated with a greater risk of noncardia gastric cancer in individuals infected with $H$. pylori [50].

Genetic factors are involved in triggering, by $\mathrm{H}$. pylori infection, premalignant lesions such as intestinal metaplasia (IM). Research on the risk factors of atrophic gastritis (AG) and IM in subjects without significant gastroduodenal diseases showed that AG was related to both $H$. pylori infection and the presence of genes encoding virulence factors such as vacA $\mathrm{m} 1$ and cagA. In contrast, the risk factors for IM were $H$. pylori infection, smoking, age over 61 years, eating spicy food, and IL-10-592 C/A [52]. These results suggest that genetic polymorphisms are associated with IM, which increases the risk of gastric cancer 10.9-fold, compared to subjects without IM [52]. Moreover, a family history of gastric cancer is not significantly associated with the incidence of AG [53].

The results of gene-association studies differ among geographic areas and ethnicities. For instance, genetic polymorphisms in IL-1 $\beta$ and TNF- $\alpha$ are consistently related to gastric cancer among Caucasians [54,55], while the effect was inconsistent among Asian patients [56,57]. In contrast, IL- $\delta$ and TGF- $\beta$ genetic polymorphisms and gastric carcinogenesis were related more consistently among Asian than Western patients [58-6o]. Moreover, since most studies did not include family history as a covariate, knowledge of its influence on the linkage between inflammation-related gene polymorphisms and susceptibility to gastric cancer is limited. According to a recent comprehensive study of 123 gastric cancer patients with a family history and 639 age- and sexmatched control gastric cancer patients without a family history [38], intestinal-type gastric cancer patients with a family history spent their youth in rural areas more frequently than did those without a family history (OR, 2.0; 95\% CI, 1.0 to 3.9), and fewer harbored TGF $31-509 \mathrm{~T}$ (OR, 0.5; 95\% CI, 0.3 to 0.9). This suggested that both environmental factors and genetic polymorphisms affect the genesis of intestinal-type gastric cancer in subjects with a family history [38]. It has been reported that matrix metalloproteinase 9 gene polymorphisms are associated with a greater risk of gastric cancer in individuals with one parent or sibling with gastric cancer compared with those with no family history [61]. 
The hypothesis that familial aggregation of gastric cancer is attributable to low-penetrance polymorphic variants has not been validated [24]. To determine the mechanism underlying the increased susceptibility to gastric cancer among subjects with a family history of the disease, environmental factors, $H$. pylori infection, and the interaction between $H$. pylori virulence factors and genetic susceptibility must be taken into consideration. Moreover, the familial clustering of gastric cancer should be investigated in genome-wide association studies.

\section{EFFECT OF FAMILY HISTORY ON THE OUT- COME OF GASTRIC CANCER}

\section{Risk for gastric cancer according to number of affected relatives or family members}

There is no definite consensus about which gastric cancer is 'familial,' other than familial gastric cancer syndrome. Although having a first-degree relative with gastric cancer is an important risk factor, the individual impact according to the number of affected relatives or the family member affected is unclear.

It is generally accepted that the risk of gastric cancer increases with an increasing number of affected relatives [23]. The risk of gastric cancer was higher in individuals with a single first-degree family member with gastric cancer (OR, 2.7; 95\% CI, 1.7 to 4.3), and increased further for subjects with two or more first-degree relatives with gastric cancer (OR, 9.6; 95\% CI, 1.2 to 73.4) [18]. Indeed, an Italian study reported that having two or more first-degree relatives with gastric cancer was associated with a greater risk of developing gastric cancer than a single first-degree relative (OR, 5.5; 95\% CI, 3.0 to 10.2 vs. OR, 1.7; 95\% CI, 1.3 to 2.1) [62]. Furthermore, a history of gastric cancer in a sibling showed a more significant association with an increased susceptibility to gastric cancer than a history of gastric cancer in a parent (sibling: OR, 2.6; 95\% CI, 1.8 to 3.7; parent: OR, 1.7; 95\% CI, 1.3 to 2.2) [62].

The adjusted risk of gastric cancer was higher for subjects with an affected mother than for those with an affected father (OR, 2.3 and 1.3), and increased further for subjects with both parents (OR, 3.0) or two or more siblings (OR, 8.5) affected by gastric cancer [62]. The risk of gastric cancer for subjects with a sibling with gastric cancer also increased significantly (OR, 2.4; 95\% CI, 1.3 to 4.7 ), but the risk was less than that of subjects with an affected parent (OR, 3.3; 95\% CI, 1.9 to 5.8) [18]. Although studies of the impact of affected siblings or parents on gastric cancer development have reported discrepant results, the higher risk of gastric cancer in those with affected mothers than affected fathers is consistent. A Korean study showed that the risk of gastric cancer was higher in subjects with an affected mother than an affected father (OR, 3.8; 95\% CI, 1.5 to 9.6 vs. OR, 2.9; $95 \%$ CI, 1.5 to 5.6) [18]. Similarly, another Korean study reported that gastric cancer patients with a maternal history had an overall larger number of affected relatives than those with an affected father, siblings, or offspring [63]. The reason for the increased risk with a history in the maternal line is unclear. The fact that maternal dietary practices strongly influence the dietary preference and nutritional status of the offspring may contribute to the maternal familial pattern. Moreover, frequent and intimate contact between mothers with their children might increase the likelihood of transmission of $\mathrm{H}$. pylori infection. Further study is needed to clarify this.

The impact of family history of gastric cancer on susceptibility to gastric cancer might differ according to gender. Nagase et al. [30] reported that family history was a stronger risk factor for females than for males (OR, 4.5 for females and 1.2 for males). This was consistent with an Italian study (OR, 2.2 for females and 1.8 for males) [62] and a Korean study (OR, 3.6 for females and 2.7 for males) [18]. Yatsuya et al. [48] also reported that a positive history of gastric cancer in one or more first-degree relatives was associated with an increased risk of the disease in females, but not in males, after controlling for $H$. pylori infection and other confounding variables. Since gastric cancer is a male-dominant disease worldwide, a family history might be more easily detected among female cases. This may be explained by gender differences in recall or styles of reporting the family history. Genetic factors might exert a greater influence on gastric carcinogenesis in female patients with a family history.

Subjects with a single first-degree affected relative may be different from those with two or more first-degree relatives with gastric cancer in terms of lifetime gastric cancer risk, impact of familial risk, or genetic factors. The clinicopathological characteristics of gastric 
cancer patients with one or two or more affected relative were compared [63]. The significant risk factors for gastric cancer in subjects with a single relative with the disease were almost identical to those in the total family history-positive subjects [63]. Only alcohol consumption was excluded from the risk factors of those in the total family history-positive subjects. However, among subjects with two or more relatives with gastric cancer, TGF $\beta 1-509 \mathrm{~T} / \mathrm{T}$, rural residency in childhood, alcohol consumption, moderate to strong spicy food ingestion and cagA positivity were risk factors for gastric cancer [63]. Alcohol consumption was associated with a more marked increase in gastric cancer risk in the group with two or more affected relatives than in the group with a single affected relative [63]. Similarly, it has been reported that matrix metalloproteinase 9 gene polymorphisms are associated with a history of gastric cancer in multiple family members [61]. This implies that 'gastric cancer patients with a family history' is a heterogeneous group that requires characterization and stratification. Thus, a detailed family history assessment of cancer patients, including the number of affected first-degree relatives, is needed to increase our understanding of familial or hereditary gastric cancer and identify genetic risk factors. Selection of patients with multiple affected relatives will facilitate evaluation of familial or hereditary cancer. However, this approach has a limitation since some patients with a single affected relative could, in future, be transferred to the group with two or more affected relatives. Recently, the Japanese National Cancer Center developed a prediction model for estimating the cumulative probability of gastric cancer occurrence based on a cohort of 19,028 individuals, using demographic and clinical variables, including a family history of gastric cancer and biological information (serum anti-H. pylori immunoglobulin G titers, levels of pepsinogen I and pepsinogen II) [64]. Further prospective studies at a nationwide level are necessary to identify individuals with a family history who are at very high risk of gastric cancer.

\section{Family history and onset of gastric cancer}

The onset of malignancy in affected relatives of young age is generally believed to be associated with a higher risk for other family members. The National Cancer Center in Korea reported that gastric cancer patients with a parent diagnosed before 50 years of age developed gastric cancer approximately 10 years earlier than individuals without a family history of gastric cancer [65]. Interestingly, early diagnosis of gastric cancer was more frequent in patients with an affected father. That is, the mean age at diagnosis in patients with a paternal history was $54.4 \pm 10.4$ years, which was significantly younger than in those without a family history $(58.1 \pm 12.0$ years, $p<0.001)[65]$. However, this finding was not the case in patients who had an affected mother (57.2 \pm 10.0 years) or sibling (62.2 \pm 9.8 years) [65]. This result is consistent with a report that gastric cancer patients with an affected father were younger than those with an affected mother (mean age, $57.0 \pm 11.4$ years vs. $62.2 \pm 9.2$ years, $p=0.012$ ) [63]. Gastric cancer patients with both parents affected were younger than those with one affected parent, suggesting an earlier age distribution of familial cases [63]. The early onset of gastric cancer in parents seems to be associated with the age of gastric cancer diagnosis (or onset) in their offspring.

A separate entity, 'early onset gastric cancer,' is defined as gastric cancer presenting at the age of $\leq 45$ years. It is characterized by a poorer prognosis in young patients, a female preponderance, and more frequent occurrence of diffuse-type cancer [66-68]. Some early onset gastric cancer cases are inherited gastric cancer syndromes [66], of whom $<10 \%$ have a family history [68]. The possibility that those with certain single genetic predisposition (inherited gastric cancer syndrome) may be incorporated into general gastric cancers cases with family history was not excluded. There is a reason why detailed information including ages at diagnosis, histology of cancer and pedigree was essential to study gastric cancers with family.

Intestinal-type gastric cancer is believed to undergo multistage carcinogenesis through AG and IM [69]; thus, which may be more frequent in subjects with a family history. According to a meta-analysis of six studies, the rates of AG and IM among subjects with family history of gastric cancer were 2.2- and 1.98-fold higher, respectively, than in subjects without a family history [15]. However, a study from Iran in 2012 reported that a family history of gastric cancer was associated with an increased incidence of IM, but not AG [70]. In addition, Oh et al. [71] reported that first-degree relatives had an adjusted OR of 2.69 (95\% CI, 1.1 to $6.8 ; p=0.037$ ) for an- 
tral IM in males in a multivariable regression analysis, but there was no such effect on AG. Indeed, analyses of endoscopic observations of 4,023 patients undergoing health screenings in Korea have showed that the risk factors for IM were similar to those of AG, but dairy product consumption (OR, 1.4) and a family history of gastric cancer (OR, 1.5) were associated only with IM [12]. According to a recent comprehensive study of 123 gastric cancer patients with a family history and 639 age- and sex-matched gastric cancer patients without a family gastric cancer history, the rate of IM in the body among patients $<50$ years old with a family history was higher than that of the patients without a family history $(p=$ 0.018) [38]. Therefore, IM occurs more frequently among individuals with a family history $[12,15,71]$.

\section{Prognosis and strategy for early diagnosis of gastric cancer in those with a family history}

The prognosis of a gastric cancer patient with affected relatives tends to be better than that of a patient without a family history $[36,72,73]$. According to a report from Korea, many gastric cancer patients with a family history exhibited shallow gastric cancer infiltration [72]. The National Cancer Center in Korea reported that patients with a family history showed better prognostic outcomes, including disease-free survival rate, recurrence-free survival rate, and overall survival rate. Interestingly, a significant prognostic improvement was observed, particularly in those with stages III and IV gastric cancer [73]. While only 55.1\% of gastric cancer patients without a family history were diagnosed with intestinal-type, $71.8 \%$ of family history-positive gastric cancer patients had intestinal-type gastric cancers $(p=$ 0.015) [73]. This was consistent with an Italian report that $71.8 \%$ of gastric cancer patients with a family history had intestinal-type gastric cancer, compared to only $55.1 \%$ of patients without a family history [74]. This might explain, in part, the favorable prognosis of gastric cancer patients with a family history. However, a Japanese study reported that the prognosis of gastric cancer patients with a family history was worse than that of patients without a family history [75]. A report from Taiwan showed that prognosis was not affected by a family history of gastric cancer [76]. These discrepancies might be caused by differences in controlling confounding factors. A recent meta-analysis of five studies showed that family histo- ry can exert beneficial effects in gastric cancer patients [77]. Subjects undertake frequent health screenings due to their family history of gastric cancer [78], show good health-related behaviors, such as non-smoking, non-alcoholic drinking and consistent exercise, and frequently have microsatellite instability and mismatch repair proteins, which are associated with a good prognosis [73].

Although many individuals with a family history are concerned about their risk of developing gastric cancer, guidelines for assessment of the family history of individuals with gastric cancer have not been developed, unlike other common cancers. Fundamentally, there has been a lack of attention to the definition of familial gastric cancer, the characteristics of gastric cancer in patients with a family history and the molecular basis of gastric cancer in a family. 'Familial' often indicates only a positive family history, while 'hereditary' suggests alterations in specific genes.

To identify subjects with a family history at very high risk of gastric cancer is of particular interest. Subjects with a family history with current or past $H$. pylori infection, with two or more first-degree affected relatives, or who are female, are more likely to develop gastric cancer compared to subjects without these factors. Subjects with any first-degree affected relative who was diagnosed with gastric cancer prior to age 50 years may need early endoscopy screening.

While more attention to 'familial gastric cancer' is necessary to assess its characteristics, the presence of a family history has little influence on the methods used for prevention of gastric cancer. Dietary modifications such as consuming fresh vegetables and fruits, minimizing salty and spicy food consumption, avoidance of smoked food, and stopping smoking are recommended [79]. Eradicating $H$. pylori is important for first-degree relatives of gastric cancer patients, particularly those in their 20 and 30 , because it can prevent progression to IM [38,8o].

The European guidelines suggest that operative link of gastritis assessment, operative link for gastric intestinal metaplasia, serum pepsinogen level, a serological $H$. pylori test and a family history of gastric cancer enable identification of those at high risk of gastric cancer [81]. This guideline recommends a gastroscopy every 3 years if a patient has broad AG or IM. In countries with a high incidence of gastric cancer, such as Korea, China, 
and Japan, periodic gastroscopy is recommended since it is cost-effective [82-86]. According to a Korean report in 2012, rates of early gastric cancer in subjects who undergo annual and biennial gastroscopies were 98.6\% and $80.7 \%$, respectively, and the rates of endoscopically treatable lesions were $56.9 \%$ and $33.3 \%$, respectively [87]. In comparison, the rate of early gastric cancer in those who underwent gastroscopies at intervals greater than 2 years was 54.6\% [87]. In addition, the 5-year survival rates of the three groups were $98.5 \%, 92.0 \%$, and $86.1 \%$, respectively [87]. Therefore, annual gastroscopies in those at high risk for gastric cancer enable detection of endoscopically treatable early gastric cancer [88]. Moreover, based on a recent study [89], Korean Americans have a gastric cancer risk more similar to that of Koreans than do Americans of European descent. Therefore, regular endoscopic screening for gastric cancer in Korean Americans should be considered.

\section{CONCLUSIONS}

Known cancer syndromes do not account for a large part of familial clustering, and no guidelines for either the assessment of the family history of individuals with gastric cancer or the screening of individuals with a family history are available. However, most studies have focused on familial gastric cancer syndrome or early onset gastric cancer rather than general gastric cancer in individuals with a family history. This lack of attention to familial clustering of gastric cancer may have ensued from the international distribution of gastric cancer; high rates in Asia, Eastern Europe, and Latin America, but relatively low rates in North America and Europe [7]. Gastric cancer in individuals with a family history can provide important information about the molecular genetic pathways involved in sporadic cancers and may enhance our understanding of gastric carcinogenesis. Therefore, more studies to clarify 'familial gastric cancer' are needed. Due to the small number of subjects with a family history, stratified analyses have been lacking. The heterogeneity among studies may have arisen from investigation of different histological types and anatomic locations, which might suggest different etiologies and genetic predispositions. Thus, a detailed family history, histological classification, age at onset of disease in both patients and their affected relatives, and a history of other cancers are necessary to discern particular gastric cancer hereditary syndrome; however, obtaining such information can be problematic. Therefore, multicenter research at a national level is warranted.

Although previous studies on single nucleotide polymorphisms (SNPs) and gastric cancer susceptibility are inconsistent, genetic factors are believed to play a pivotal role in familial clustering of diseases. As high-throughput genotyping methods become more available, genome-wide association study have been conducted more frequently. This may result in the classification of gastric cancers in individuals with a family history being based on genetic markers rather than the family history and morphology, which will improve our understanding of gastric carcinogenesis.

Moreover, since low-penetrant genetic effects of SNPs could depend on interactions with a particular dietary factor, smoking or alcohol consumption, knowledge of the functional relevance of SNPs will be more critical with the incorporation of new technology for the assessment of continuous, daily exposure to dietary or environmental factors on a basis of 'big data.'

\section{Conflict of interest}

No potential conflict of interest relevant to this article was reported.

\section{REFERENCES}

1. Ferlay J, Soerjomataram I, Ervik M, et al. GLOBOCAN 2012 v1.o, Cancer Incidence and Mortality Worldwide: IARC CancerBase No. 11 [Internet]. Lyon (FR): International Agency for Research on Cancer, c2016 [cited 2016 Oct 17]. Available from: http://globocan.iarc.fr.

2. Inoue M, Tsugane S. Epidemiology of gastric cancer in Japan. Postgrad Med J 2005;81:419-424.

3. Shin HR, Won YJ, Jung KW, et al. Nationwide cancer incidence in Korea, 1999-2001; first result using the national cancer incidence database. Cancer Res Treat 2005;37:325331.

4. Lauren P. The two histological main types of gastric carcinoma: diffuse and so-called intestinal-type carcinoma. An attempt at a histo-clinical classification. Acta Pathol Microbiol Scand 1965;64:31-49. 
5. Suzuki H, Iwasaki E, Hibi T. Helicobacter pylori and gastric cancer. Gastric Cancer 2009;12:79-87.

6. Huang JQ, Sridhar S, Chen Y, Hunt RH. Meta-analysis of the relationship between Helicobacter pylori seropositivity and gastric cancer. Gastroenterology 1998;114:11691179 .

7. Yaghoobi M, Bijarchi R, Narod SA. Family history and the risk of gastric cancer. Br J Cancer 2010;102:237-242.

8. Oliveira C, Pinheiro H, Figueiredo J, Seruca R, Carneiro F. Familial gastric cancer: genetic susceptibility, pathology, and implications for management. Lancet Oncol 2015;16:e6o-e7o.

9. Lee HJ, Yang HK, Ahn YO. Gastric cancer in Korea. Gastric Cancer 2002;5:177-182.

10. McLean MH, El-Omar EM. Genetics of gastric cancer. Nat Rev Gastroenterol Hepatol 2014;11:664-674.

11. Lim SH, Kwon JW, Kim N, et al. Prevalence and risk factors of Helicobacter pylori infection in Korea: nationwide multicenter study over 13 years. BMC Gastroenterol 2013;13:104.

12. Joo YE, Park HK, Myung DS, et al. Prevalence and risk factors of atrophic gastritis and intestinal metaplasia: a nationwide multicenter prospective study in Korea. Gut Liver 2013;7:303-310.

13. Corso G, Marrelli D. Frequency of familial gastric cancer. In: Corso G, Roviello F, eds. Spotlight on Familial and Hereditary Gastric Cancer. Dordrecht: Springer, 2013:1118.

14. Zanghieri G, Di Gregorio C, Sacchetti C, et al. Familial occurrence of gastric cancer in the 2-year experience of a population-based registry. Cancer 1990;66:2047-2051.

15. Rokkas T, Sechopoulos P, Pistiolas D, Margantinis G, Koukoulis G. Helicobacter pylori infection and gastric histology in first-degree relatives of gastric cancer patients: a meta-analysis. Eur J Gastroenterol Hepatol 2010;22:1128-1133.

16. Chang YW, Han YS, Lee DK, et al. Role of Helicobacter pylori infection among offspring or siblings of gastric cancer patients. Int J Cancer 2002;101:469-474.

17. Brenner H, Arndt V, Sturmer T, Stegmaier C, Ziegler H, Dhom G. Individual and joint contribution of family history and Helicobacter pylori infection to the risk of gastric carcinoma. Cancer 2000;88:274-279.

18. Shin CM, Kim N, Yang HJ, et al. Stomach cancer risk in gastric cancer relatives: interaction between Helicobacter pylori infection and family history of gastric can- cer for the risk of stomach cancer. J Clin Gastroenterol 2010;44:e34-e39.

19. Eto K, Ohyama S, Yamaguchi T, et al. Familial clustering in subgroups of gastric cancer stratified by histology, age group and location. Eur J Surg Oncol 2006;32:743-748.

20. Ikeguchi M, Fukuda K, Oka S, et al. Clinicopathological findings in patients with gastric adenocarcinoma with familial aggregation. Dig Surg 2001;18:439-443.

21. Huang X, Tajima K, Hamajima N, et al. Effect of life styles on the risk of subsite-specific gastric cancer in those with and without family history. J Epidemiol 1999;9:40-45.

22. Lissowska J, Groves FD, Sobin LH, et al. Family history and risk of stomach cancer in Warsaw, Poland. Eur J Cancer Prev 1999;8:223-227.

23. La Vecchia C, Negri E, Franceschi S, Gentile A. Family history and the risk of stomach and colorectal cancer. Cancer 1992;70:50-55.

24. Garcia-Gonzalez MA, Lanas A, Quintero E, et al. Gastric cancer susceptibility is not linked to pro-and anti-inflammatory cytokine gene polymorphisms in whites: a Nationwide Multicenter Study in Spain. Am J Gastroenterol 2007;102:1878-1892.

25. Bakir T, Can G, Erkul S, Siviloglu C. Stomach cancer history in the siblings of patients with gastric carcinoma. Eur J Cancer Prev 2000;9:401-408.

26. Bakir T, Can G, Siviloglu C, Erkul S. Gastric cancer and other organ cancer history in the parents of patients with gastric cancer. Eur J Cancer Prev 2003;12:183-189.

27. Dhillon PK, Farrow DC, Vaughan TL, et al. Family history of cancer and risk of esophageal and gastric cancers in the United States. Int J Cancer 2001;93:148-152.

28. Gajalakshmi CK, Shanta V. Lifestyle and risk of stomach cancer: a hospital-based case-control study. Int J Epidemiol 1996;25:1146-1153.

29. Minami Y, Tateno H. Associations between cigarette smoking and the risk of four leading cancers in Miyagi Prefecture, Japan: a multi-site case-control study. Cancer Sci 2003;94:540-547.

30. Nagase H, Ogino K, Yoshida I, et al. Family history-related risk of gastric cancer in Japan: a hospital-based case-control study. Jpn J Cancer Res 1996;87:1025-1028.

31. Hong SH, Kim JW, Kim HG, et al. Glutathione S-transferases (GSTM1, GSTT1 and GSTP1) and N-acetyltransferase 2 polymorphisms and the risk of gastric cancer. J Prev Med Public Health 2006;39:135-140.

32. Chen MJ, Wu DC, Ko YC, Chiou YY. Personal history and 
family history as a predictor of gastric cardiac adenocarcinoma risk: a case-control study in Taiwan. Am J Gastroenterol 2004;99:1250-1257.

33. Gong EJ, Ahn JY, Jung HY, et al. Risk factors and clinical outcomes of gastric cancer identified by screening endoscopy: a case-control study. J Gastroenterol Hepatol 2014;29:301-309.

34. Safaee A, Moghimi-Dehkordi B, Fatemi SR, Maserat E, Zali MR. Family history of cancer and risk of gastric cancer in Iran. Asian Pac J Cancer Prev 2011;12:3117-3120.

35. Foschi R, Lucenteforte E, Bosetti C, et al. Family history of cancer and stomach cancer risk. Int J Cancer 2008;123:1429-1432.

36. Palli D, Russo A, Saieva C, Salvini S, Amorosi A, Decarli A. Dietary and familial determinants of 10-year survival among patients with gastric carcinoma. Cancer 2000; 89:1205-1213.

37. Palli D, Russo A, Ottini L, et al. Red meat, family history, and increased risk of gastric cancer with microsatellite instability. Cancer Res 2001;61:5415-5419.

38. Shin CM, Kim N, Lee HS, et al. Intrafamilial aggregation of gastric cancer: a comprehensive approach including environmental factors, Helicobacter pylori virulence, and genetic susceptibility. Eur J Gastroenterol Hepatol 2011;23:411-417.

39. Hemminki K, Sundquist J, Ji J. Familial risk for gastric carcinoma: an updated study from Sweden. Br J Cancer 2007;96:1272-1277.

40. Yim JY, Kim N, Choi SH, et al. Seroprevalence of Helicobacter pylori in South Korea. Helicobacter 2007;12:333-340.

41. Kim JH, Kim HY, Kim NY, et al. Seroepidemiological study of Helicobacter pylori infection in asymptomatic people in South Korea. J Gastroenterol Hepatol 2001;16:969-975.

42. Bures J, Kopacova M, Koupil I, et al. Epidemiology of Helicobacter pylori infection in the Czech Republic. Helicobacter 2006;11:56-65.

43. Bures J, Kopacova M, Koupil I, et al. Significant decrease in prevalence of Helicobacter pylori in the Czech Republic. World J Gastroenterol 2012;18:4412-4418.

44. Leung WK, Ng EK, Lam CC, et al. Helicobacter pylori infection in 1st degree relatives of Chinese gastric cancer patients. Scand J Gastroenterol 2006;41:274-279.

45. Brenner $\mathrm{H}$, Bode $\mathrm{G}$, Boeing $\mathrm{H}$. Helicobacter pylori infection among offspring of patients with stomach cancer. Gastroenterology 2000;118:31-35.
46. Queiroz DM, Silva CI, Goncalves MH, et al. Higher frequency of cagA EPIYA-C phosphorylation sites in $\mathrm{H}$. pylori strains from first-degree relatives of gastric cancer patients. BMC Gastroenterol 2012;12:107.

47. Siavoshi F, Asgharzadeh A, Ghadiri H, Massarrat S, Latifi-Navid S, Zamani M. Helicobacter pylori genotypes and types of gastritis in first-degree relatives of gastric cancer patients. Int J Med Microbiol 2011;301:506-512.

48. Yatsuya H, Toyoshima H, Tamakoshi A, et al. Individual and joint impact of family history and Helicobacter pylori infection on the risk of stomach cancer: a nested case-control study. Br J Cancer 2004;91:929-934.

49. El-Omar EM, Carrington M, Chow WH, et al. Interleukin-1 polymorphisms associated with increased risk of gastric cancer. Nature 2000;404:398-402.

50. El-Omar EM, Rabkin CS, Gammon MD, et al. Increased risk of noncardia gastric cancer associated with proinflammatory cytokine gene polymorphisms. Gastroenterology 2003;124:1193-1201.

51. Canedo P, Figueiredo C, Machado JC. After Helicobacter pylori, genetic susceptibility to gastric carcinoma revisited. Helicobacter 2007;12 Suppl 2:45-49.

52. Kim N, Park YS, Cho SI, et al. Prevalence and risk factors of atrophic gastritis and intestinal metaplasia in a Korean population without significant gastroduodenal disease. Helicobacter 2008;13:245-255.

53. Adamu MA, Weck MN, Rothenbacher D, Brenner H. Incidence and risk factors for the development of chronic atrophic gastritis: five year follow-up of a population-based cohort study. Int J Cancer 2011;128:1652-1658.

54. Kamangar F, Cheng C, Abnet CC, Rabkin CS. Interleukin-1B polymorphisms and gastric cancer risk: a meta-analysis. Cancer Epidemiol Biomarkers Prev 2006; 15:1920-1928.

55. Gorouhi F, Islami F, Bahrami H, Kamangar F. Tumour-necrosis factor-A polymorphisms and gastric cancer risk: a meta-analysis. Br J Cancer 2008;98:1443-1451.

56. Lee SG, Kim B, Choi W, Lee I, Choi J, Song K. Lack of association between pro-inflammatory genotypes of the interleukin-1 (IL-1B -31 C/+ and IL-1RN *2/ ${ }_{2}$ ) and gastric cancer/duodenal ulcer in Korean population. Cytokine 2003;21:167-171.

57. Kim N, Cho SI, Yim JY, et al. The effects of genetic polymorphisms of IL-1 and TNF-A on Helicobacter pylori-induced gastroduodenal diseases in Korea. Helicobacter 2006;11:105-112. 
58. Savage SA, Abnet CC, Mark SD, et al. Variants of the IL8 and IL8RB genes and risk for gastric cardia adenocarcinoma and esophageal squamous cell carcinoma. Cancer Epidemiol Biomarkers Prev 2004;13:2251-2257.

59. Song JH, Kim SG, Jung SA, Lee MK, Jung HC, Song IS. The interleukin-8-251 AA genotype is associated with angiogenesis in gastric carcinogenesis in Helicobacter pylori-infected Koreans. Cytokine 2010;51:158-165.

6o. Jin G, Wang L, Chen W, et al. Variant alleles of TGFB1 and TGFBR2 are associated with a decreased risk of gastric cancer in a Chinese population. Int J Cancer 2007;120:13301335 .

61. Okada R, Naito M, Hattori Y, et al. Matrix metalloproteinase 9 gene polymorphisms are associated with a multiple family history of gastric cancer. Gastric Cancer 2016 Apr 6 [Epub]. http://dx.doi.org/10.1007/s10120-016-0608-2.

62. Palli D, Galli M, Caporaso NE, et al. Family history and risk of stomach cancer in Italy. Cancer Epidemiol Biomarkers Prev 1994;3:15-18.

63. Choi YJ, Kim N, Jang W, et al. Familial clustering of gastric cancer: a retrospective study based on the number of first-degree relatives. Medicine (Baltimore) 2016;95:e3606.

64. Charvat H, Sasazuki S, Inoue M, et al. Prediction of the 10-year probability of gastric cancer occurrence in the Japanese population: the JPHC study cohort II. Int J Cancer 2016;138:320-331.

65. Kwak HW, Choi IJ, Kim CG, et al. Individual having a parent with early-onset gastric cancer may need screening at younger age. World J Gastroenterol 2015;21:4592-4598.

66. Lim S, Lee HS, Kim HS, Kim YI, Kim WH. Alteration of E-cadherin-mediated adhesion protein is common, but microsatellite instability is uncommon in young age gastric cancers. Histopathology 2003;42:128-136.

67. Matley PJ, Dent DM, Madden MV, Price SK. Gastric carcinoma in young adults. Ann Surg 1988;208:593-596.

68. Kokkola A, Sipponen P. Gastric carcinoma in young adults. Hepatogastroenterology 2001;48:1552-1555.

69. Correa P. Human gastric carcinogenesis: a multistep and multifactorial process: first American Cancer Society Award Lecture on Cancer Epidemiology and Prevention. Cancer Res 1992;52:6735-6740.

70. Mansour-Ghanaei F, Joukar F, Baghaei SM, et al. Gastric precancerous lesions in first degree relatives of patients with known gastric cancer: a cross-sectional prospective study in Guilan Province, north of Iran. Asian Pac J Cancer Prev 2012;13:1779-1782.
71. Oh S, Kim N, Yoon H, et al. Risk factors of atrophic gastritis and intestinal metaplasia in first-degree relatives of gastric cancer patients compared with age-sex matched controls. J Cancer Prev 2013;18:149-160.

72. Park SH, Yu W, Chung HY. Characteristics of gastric cancer patients with family history. J Korean Surg Soc 2001;60:309-313.

73. Han MA, Oh MG, Choi IJ, et al. Association of family history with cancer recurrence and survival in patients with gastric cancer. J Clin Oncol 2012;30:701-708.

74. Bernini M, Barbi S, Roviello F, et al. Family history of gastric cancer: a correlation between epidemiologic findings and clinical data. Gastric Cancer 2006;9:9-13.

75. Yatsuya H, Toyoshima H, Mizoue T, et al. Family history and the risk of stomach cancer death in Japan: differences by age and gender. Int J Cancer 2002;97:688-694.

76. Lee WJ, Hong RL, Lai IR, Chen CN, Lee PH, Huang MT. Clinicopathologic characteristics and prognoses of gastric cancer in patients with a positive familial history of cancer. J Clin Gastroenterol 2003;36:30-33.

77. Oh MG, Kim JH, Han MA, Park J, Ryu SY, Choi SW. Family history and survival of patients with gastric cancer: a meta-analysis. Asian Pac J Cancer Prev 2014;15:3465-3470.

78. Kang JM, Shin DW, Kwon YM, et al. Stomach cancer screening and preventive behaviors in relatives of gastric cancer patients. World J Gastroenterol 2011;17:3518-3525.

79. Compare D, Rocco A, Nardone G. Risk factors in gastric cancer. Eur Rev Med Pharmacol Sci 2010;14:302-308.

8o. Fock KM, Talley N, Moayyedi P, et al. Asia-Pacific consensus guidelines on gastric cancer prevention. J Gastroenterol Hepatol 2008;23:351-365.

81. Dinis-Ribeiro M, Areia M, de Vries AC, et al. Management of precancerous conditions and lesions in the stomach (MAPS): guideline from the European Society of Gastrointestinal Endoscopy (ESGE), European Helicobacter Study Group (EHSG), European Society of Pathology (ESP), and the Sociedade Portuguesa de Endoscopia Digestiva (SPED). Virchows Arch 2012;460:19-46.

82. Tashiro A, Sano M, Kinameri K, Fujita K, Takeuchi Y. Comparing mass screening techniques for gastric cancer in Japan. World J Gastroenterol 2006;12:4873-4874.

83. Dan YY, So JB, Yeoh KG. Endoscopic screening for gastric cancer. Clin Gastroenterol Hepatol 2006;4:709-716.

84. Mori Y, Arita T, Shimoda K, Yasuda K, Yoshida T, Kitano S. Effect of periodic endoscopy for gastric cancer on early detection and improvement of survival. Gastric Cancer 
2001;4:132-136.

85. Aida K, Yoshikawa H, Mochizuki C, et al. Clinicopathological features of gastric cancer detected by endoscopy as part of annual health checkup. J Gastroenterol Hepatol 2008;23:632-637.

86. Nam SY, Choi IJ, Park KW, et al. Effect of repeated endoscopic screening on the incidence and treatment of gastric cancer in health screenees. Eur J Gastroenterol Hepatol 2009;21:855-86o.

87. Chung SJ, Park MJ, Kang SJ, et al. Effect of annual endo- scopic screening on clinicopathologic characteristics and treatment modality of gastric cancer in a high-incidence region of Korea. Int J Cancer 2012;131:2376-2384.

88. Yoon H, Kim N. Diagnosis and management of high risk group for gastric cancer. Gut Liver 2015;9:5-17.

89. Kim GH, Bang SJ, Ende AR, Hwang JH. Is screening and surveillance for early detection of gastric cancer needed in Korean Americans? Korean J Intern Med 2015;30:747758. 